\title{
Prevalence of Depression among Patients with Diabetes Mellitus Type 2 Attending a Tertiary Care Teaching Hospital in Oman
}

\author{
Sumaia Al Saadi ${ }^{1}$, Salima Al Musharrafi ${ }^{1}$, Ali Saif Al Mamari ${ }^{2}$, Sathiya Murthi Panchatcharam ${ }^{3}$, Sangeetha Mahadevan ${ }^{4}$ and Samir \\ Al-Adawi ${ }^{4 *}$ \\ ${ }^{1}$ Oman Medical Specialty Board, North Azaiba, Muscat, Oman \\ ${ }^{2}$ Department of Medicine, College of Medicine \& Health Sciences, Sultan Qaboos University, Muscat 123, Oman \\ ${ }^{3}$ Research Section, Oman Medical Specialty Board, North Azaiba, Muscat, Oman \\ ${ }^{4}$ Department of Behavioral Medicine, College of Medicine \& Health Sciences, Sultan Qaboos University, Muscat, Oman
}

${ }^{\star}$ Corresponding author: Saleema Musharrafi, Psychiatry Residency Program, Oman Medical Speciality Board, Muscat, Sultanate of Oman, Oman; Tel: 0096896446048; Email: drsaleema@hotmail.com

Received: February 04, 2022; Accepted: February 10, 2022; Published: February 11, 2022

\begin{abstract}
Background: Presently, there is an abundance of research indicating that depressive symptoms are a common occurrence in people with Diabetes Mellitus (T2DM). However, the mechanism by which this occurs is yet to be established. And although many studies of this sort have emerged the world over, this topic has still been under-researched in the Arabian Gulf, a region with a high preponderance of T2DM.
\end{abstract}

Aims: To establish the psychometric properties of an instrument for soliciting depressive symptoms among patients with T2DM, to calculate the prevalence of depressive symptoms and to tease out the factors that contribute to variations in depressive symptoms.

Method: A receiver operating characteristic (ROC) analysis was conducted to establish the cut-off for case-ness or otherwise. Variations in depressive symptoms were solicited using the Beck Depression Inventory (BDI-21) and clinical variables and risk factors were sought from medical records.

Results: One hundred and four individuals fulfilled the study criteria (response rate $=69 \%$ ). The ROC-suggested cut-off $\geq 13$ on the BDI-21 matched with $94 \%$ sensitivity and $71 \%$ specificity. Using this cut-off, $7.7 \%$ of the sample endorsed depressive symptoms. Age, marital status, and income were found to strongly moderate the depressive symptoms.

Conclusion: The low prevalence rate observed in the present study places the results of this study on the lower ranges when compared to the international trend. Nevertheless, mechanisms are needed to mitigate the presence of depressive symptoms among people seeking consultation in diabetic clinics in Oman.

Fefty

Globally, Diabetes Mellitus (T2DM) is increasingly being recognized as a life-limiting disease, fulfilling all the characteristics of a multimorbidity condition $[1,2]$. T2DM has become a fairly common non-communicable disease in many emerging economies and Oman is no exception [3]. According to the Diabetes Atlas, a nationally representative survey has indicated $10.7 \%$ of Omanis to have T2DM [4]. This figure, however, is likely to be an underestimation of the magnitude since the available numbers have been based on oral glucose tolerance tests. The current predictions are bleak as the region that includes Oman is expected to have a $110 \%$ increase in the number of people with T2DM by 2045 [4]

Despite their amorphous nature, depressive symptoms have now been recognized as being common among people with T2DM [5]. Depressive symptoms also tend to heighten the risk of diabetes complications and, in that regard, act as the harbingers of poor quality of life along with the morbidity and mortality [6]. Available literature has unequivocally suggested that depressive symptoms are nonulation [7] A narticularly disheartening circumstance is that the presence of the two conditions of T2DM and depression can have the mutual negative effect of one heightening the other, together with leading to poor quality of life and mortality [8]. Most studies examining the presence of depression in T2DM generally emanate from Western Europe and the North American and Asian Pacific regions [9]. Recent systematic reviews and meta-analyses [2] have all indicated the lack of studies from developing economies. Most significantly, a majority of studies have quantified the presence of depression without considering the application of the measures tapping into depressive symptoms [2]. To fill this gap in the literature, this study aimed to (i) establish the psychometric properties of BDI-21 among attendees with T2DM, (ii) to solicit the prevalence of depressive symptoms, and (iii) to tease out the factors contributing to variations in depressive symptoms.

\section{Methods}

\section{Study Setting, Time, and Participants}

This cross-sectional study was conducted between March and May 
2017. All participants were among attendees seeking consultation from a diabetes clinic at a teaching hospital located in the nation's capital, Muscat. The algorithm for the universal free healthcare system for all citizens in Oman is divided into three tiers. The first tier constitutes primary healthcare centers that are distributed across all regions of the country. The second tier constitutes secondary care where they cater to referrals from primary healthcare centers. The final tier is the tertiary care sector with a catchment area of referrals from all over the country. The patients here are usually those with more intransigent and debilitating types of illnesses that often require specialized services. Individuals are also referred here for diagnostic or scanning purposes.

Participants who fulfilled the inclusion criteria and agreed to participate in this study were asked to sign an informed consent form. They were then handed out the study proforma. A research assistant oversaw the process in a private room where the consenting participant completed the questionnaire by themselves.

\section{Inclusion/Exclusion criteria}

All patients attending the clinic during the study period diagnosed with T2DM and were over 18 years of age were included in this study. Exclusion criteria entailed pregnancy or a previous diagnosis of a severe mental illness.

\section{Sample Size and Sampling Method}

The required sample size was calculated using Open Epi software. Following this, the prevalence of depression among patients with T2DM was considered to be around $10 \%$ with a precision of $5 \%$ and a confidence interval level of $95 \%$. It was calculated that the minimum sample size required for this study was 139. A total of 104 participants were able to fill the questionnaire from the distribution of 150 .

\section{Outcome Measure}

The Arabic-version of the Beck Depression Inventory scale (BDI-21) was employed to solicit the presence of depressive symptoms. The BDI has been extensively used among Arabic- speaking populations using various dialects $[10,11]$. However, existing literature has not identified the optimal cut-off point of BDI-21 for Omanis. In order to fill this gap in existing literature, this study has embarked to establish the psychometric property of BDI-21 among people with T2DM. As the background for this study, a 2-phase survey using receiver operating characteristic (ROC) analysis was conducted to shed light on the sensitivity and specificity of Arabic-version of BDI-21 [12]. Patients with T2DM ( $\mathrm{n}=75)$ were examined for the presence of depressive symptoms using the protocol exemplified by our previous studies $[13,14]$. The Composite International Diagnostic Interview (CIDI) was operationalized as the gold-standard for depressive symptoms for this study $[15,16]$. The researcher performed CIDI 'blinded' from the score of BDI-21. Among the pooled scores from CIDI and BDI-21, the ROC curve was calculated to discriminate between the sensitivity and specificity for BDI-21 for every possible threshold score. This protracted exercise suggested that a cut-off of $\geq 13$ on the BDI- 21 yielded $94 \%$ sensitivity and $71 \%$ specificity. Thus, $\geq 13$ appears to adequately vet case-ness and non-case-ness.
In addition to the BDI, the study proforma, designed to obtain information regarding participants' demographic and clinical variables, contained the following: Gender ( 'Male,' 'Female'), Marital status ('married', 'single, 'divorced', 'widowed'), duration of diagnosis in years, current treatment intake ('tablets', 'injections', and 'both'), having other diseases ('heart disease, 'hyperlipidemia,' 'others'), having Complications of DMT2 ('yes', 'no'), having a positive family history of the depressive symptom ('yes', 'no'). Due to the lack of a standardized calculation for socioeconomic status, the patient's monthly income was solicited and calculated in Oman Rials (OMR): '<500 OMR', 5011000 OMR, >1000 OMR). In comparison to US currency, the present level of income corresponds to approximately 1298 USD, 1298-2596 USD, and 2596 USD, respectively. In general, those with $\leq 500$ OMR were considered to be low-income.

\section{Data Collection}

\section{Ethics and Ethical Considerations}

This work has been granted ethical approval by the Ethics Committee of the College of Medicine \& Health Sciences, Sultan Qaboos University (SQU-EC/045/17). Following best practice, any participant who scored above $\geq 13$ on the BDI- 21 was referred to the treatment team for further assessment and appropriate management.

\section{Statistical Analysis}

A descriptive analysis of the categorized variables was presented as numbers and percentages and continuous variables were reported as mean and standard deviation. The prevalence was presented as a percentage with a $95 \%$ confidence interval $(95 \% \mathrm{CI})$. The association between depression and demographic factors was compared using the Chi-squared test and the Mann-Whitney test. A $p$-value $<0.05$ was considered to be statistically significant.

\section{Result}

Table 1 presents the demographic characteristics of the participants. A total of 104 participants were able to complete the questionnaire, resulting in a response rate of about $69 \%(104 / 150)$. The mean age was 43 and about two-thirds of them were married. In terms of socio-economic status, which for the present purpose was calculated in terms of income, half the participants were categorized as having the low income ( $<500$ OMR). About $8 \%$ (95\% C.I. 3.4-14.6) of the participants were diagnosed with a complication of DM, $3 \%$ were diagnosed with depression and $1 \%$ had a severe type of depression.

Table 2 demonstrates the association between depression and demographic factors of the participants. On one hand, a statistically significant association was observed between their age, marital status, and income. There was also a statistically significant difference observed between depressed and non-depressed groups in their mean age, 44 years, and 32 years, respectively. Participants with "Single" marital status showed higher levels of depression as compared to those that were married. On the other hand, no association was found between having a BDI-21 score $(\geq 13)$ and the treatment of diabetes or its complications. 
Table 1: Distribution of demographic and clinical variables among attendees at a diabetic clinic in a tertiary care center in Oman.

\begin{tabular}{|l|c|c|}
\hline Variables & $\mathbf{n}$ & $\mathbf{2}$ \\
\hline Age (Mean (sd)) & 43.08 & $(10.34)$ \\
\hline Gender & & \\
Male & 56 & 53.8 \\
Female & 48 & 46.2 \\
\hline Marital status & & \\
Married & 82 & 78.8 \\
Single & 15 & 14.4 \\
Divorced & 2 & 1.9 \\
Widowed & 5 & 4.8 \\
\hline Income (OMR) & & \\
$<500$ & 51 & 49.5 \\
$501-1000$ & 31 & 30.1 \\
$>1000$ & 21 & 20.4 \\
\hline When did you diagnose with DM in years (median, IQR) & \multicolumn{2}{|c|}{$6(3,10)$} \\
\hline Treatment of DM & & \\
Tablets & 52 & 50.5 \\
Injections & 25 & 24.3 \\
Both & 26 & 25.2 \\
\hline Other diseases & & \\
HTN & 18 & 17.6 \\
Heart disease & 3 & 2.9 \\
Hyperlipidemia & 7 & 6.9 \\
Others & 74 & 72.5 \\
\hline Complications of DM & & \\
Yes & 8 & 7.8 \\
No & 95 & 92.8 \\
\hline Have you ever diagnosed with depression? & 3 & \\
Yes & 99 & 97.9 \\
No & & \\
\hline Has anyone in the family has ever been diagnosed with depression? & 4 & 3.9 \\
Yes & 99 & 96.1 \\
No & & \\
\hline BDI-21 & & 7.7 \\
<13 (Non-caseness) & & \\
$\geq 13$ (Caseness) & & \\
\hline
\end{tabular}

Table 2: Association between demographic factors and depressive symptoms among attendees at a diabetic clinic in a tertiary care center in Oman

\begin{tabular}{|c|c|c|c|c|c|}
\hline \multirow[b]{3}{*}{ Variables } & \multicolumn{4}{|c|}{ Depression status } & \multirow[b]{3}{*}{ p-value } \\
\hline & \multicolumn{2}{|c|}{ No depression } & \multicolumn{2}{|c|}{ Depressed } & \\
\hline & $\mathbf{n}$ & $\%$ & $\mathbf{n}$ & $\%$ & \\
\hline Age (Mean, sd) & \multicolumn{2}{|c|}{$44.0(9.49)$} & \multicolumn{2}{|c|}{$31.9(14.1)$} & $0.018^{*}$ \\
\hline \multicolumn{6}{|l|}{ Gender } \\
\hline Male & 53 & 94.6 & 3 & 5.4 & \\
\hline Female & 43 & 89.6 & 5 & 10.4 & 0.466 \\
\hline \multicolumn{6}{|l|}{ Marital Status } \\
\hline Single & 11 & 73.3 & 4 & 26.7 & \\
\hline Married & 85 & 95.5 & 4 & 4.5 & 0.014 \\
\hline \multicolumn{6}{|l|}{ Income (OMR) } \\
\hline$<500$ & 47 & 92.2 & 4 & 7.8 & \\
\hline $501-1000$ & 31 & 100.0 & - & - & \\
\hline$>1000$ & 17 & 81.0 & 4 & 19.0 & 0.021 \\
\hline \multicolumn{6}{|l|}{ Treatment of DM } \\
\hline Tablets & 50 & 96.2 & 2 & 3.8 & \\
\hline Injections & 21 & 84.0 & 4 & 16.0 & \\
\hline Both & 25 & 96.2 & 1 & 3.8 & 0.154 \\
\hline \multicolumn{6}{|l|}{ Complications of DM } \\
\hline Yes & 6 & 75.0 & 2 & 25.0 & \\
\hline No & 90 & 94.7 & 5 & 5.3 & 0.091 \\
\hline \multicolumn{6}{|l|}{ Have you ever diagnosed with depression? } \\
\hline Yes & 2 & 66.7 & 1 & 33.3 & \\
\hline No & 93 & 93.9 & 6 & 6.1 & 0.194 \\
\hline \multicolumn{6}{|l|}{$\begin{array}{l}\text { Has anyone in the family has ever been } \\
\text { diagnosed with depression? }\end{array}$} \\
\hline Yes & 4 & 100.0 & - & - & \\
\hline No & 92 & 92.9 & 7 & 7.1 & 1.000 \\
\hline
\end{tabular}

\section{Discussion}

The primary goals of this study included (i) establishing the psychometric properties of the Beck Depression Inventory scale (BDI-21), (ii) soliciting the prevalence of depressive symptoms, and (iii) teasing out the factors contributing to variations in depressive symptoms.

To lay the groundwork for the present study, it was essential to establish the psychometric property of the BDI-2I. From the protracted exercise via receiver operating characteristic (ROC) analysis, a cutoff of $\geq 13$ on the BDI- 21 appeared to optimally balance sensitivity and specificity. The establishment of an optimal cut-off point for BDI21 has been marred with inconsistent results $[10,11]$. This implies a lack of agreement on the differentiation between a case and noncase. In their systematic review of studies examining the prevalence of depressive symptoms in non-western countries, Mendenhall et al. [9] identified 'fifteen depression inventories' used to solicit depressive symptoms in T2DM.

A previous study in Oman has suggested that the prevalence of T2DM in Oman has been recorded to range from $10.4 \%$ to $21.1 \%$ [17]. The data on the prevalence of depressive symptoms among people with T2DM has not been forthcoming in Oman. Among medical clinic attendees, the prevalence of depressive symptoms was reported to be $8.1 \%$ [18]. This study suggests that $7.7 \%$ of the participants with $\mathrm{T} 2 \mathrm{DM}$ endorsed themselves of having depressive symptoms using the presently defined cut-off $\geq 13$. Since the magnitude of depressive symptoms differ by measures employed to solicit the presence of depression [2], the present pursuit of comparison with the international trend will focus on the BDI-21. Previously the focus on the depressive symptoms among people with T2DM has been limited to the Western European, Northern American and Asian-Pacific regions where studies have predominantly utilized the Center for Epidemiologic Studies - Depression (CESD) scale [2]. Some studies from developing economies that utilized BDI-21 have emerged. In the UAE, $17 \%$ of the attendees of diabetic clinics in one of the principalities of UAE endorsed depressive symptoms [19] while Iran, Lebanon and Saudi Arabia have reported 46.3\% [20], 28.8\% [21] and 37.9\% [22] respectively. In the Indian State of West Bengal, a percentage of $38.8 \%$ [23] was reported. These studies from the aforementioned emerging economies have suggested higher percentages than the present study. According to a recent systematic review and meta-analysis [2], in general, most of the studies examining depressive symptoms in T2DM are fraught with spurious results.

The final interrelated aim of this study was to tease the sociodemographic factors that contributed to endorsing the presence of depressive symptoms. Socio-demographic variables tend to have a direct bearing on functionality and quality of life [24]. This study suggested that age strongly contributed to the presence of depressive symptoms. In Oman, there is emerging evidence to suggest that T2DM is increasingly affecting younger populations [25]. This identification of age as part of the trajectory of T2DM and depressive symptoms has been previously noted in other studies [26,27]. It is the younger generations that are typically expected to contribute to the future of an emerging economy. According to Erik Erikson [28], such an age 
group is also expected to undergo important milestones, namely, the consolidation of relationships with others. Hence, the presence of diabetes and the complications it entails at a young age is likely to dent the quality of this important milestone and cause the development of afflictive emotion. The second socio-demographic factor that was associated with depressive symptoms was marital status. The present data suggest that those identifying as being "single" showed higher rates of depression as compared to those that were married. Previous studies have suggested that the score of depressive symptoms are often moderated by marital status [29]. Another socio-demographic variable commonly associated with depressive symptoms is income. In today's capitalist, modern cash economy, income is known to define one's identity and it is therefore not surprising that variations in income affect the trajectory of depressive symptoms and T2DM. The present findings appear consistent with findings from other studies. For example, Dismuke \& Egede [30] reported that T2DM and depressive symptoms are associated with lower personal income in a US population.

\section{Limitations}

Much like any such scientific venture of this sort, this study too had its limitations. Firstly, the present cohort comprised of those seeking consultation from a specialized clinic, thus potentially restricting the generalizability of this study. Being in tertiary care might imply that the patient's condition was more debilitating and intransigent, hence requiring specialized care. One way to circumvent the present limitation is for future studies to recruit people with diabetes in the community. Such an undertaking is certainly warranted. Secondly, the response rate $(69 \%)$ in this study appears to fall short of the required threshold of $\geq 75$. Therefore, the generality of this study should once again be considered with caution. Third, this study has explored the cut-off point for the BDI-21, but the instrument could be hampered by certain subtle conceptual misunderstandings as well as perceptions associated with mental illness. Many studies from the current regions have suggested depressive symptoms that are often equated with weakness of character and thus stigma is rife. Relevant to this, previous studies have suggested that psychological symptoms, an integral part of BDI-21, are not endorsed. Existing socio-cultural beliefs have led to the use of somatic language to explain the manifestation of psychological distress. This might explain why the cut-off of BDI-21 was generally low compared to other studies. The BDI-21 has a twofactored structure, namely, psychological and somatic symptoms of depression [31]. Studies that explore whether non-somatic symptoms of BDI-17 are less endorsed in those societies where distress is often expressed in somatic terms are certainly required.

\section{Conclusion}

This study embarked on establishing the optimal cut-off point for BDI. The prevalence of depressive symptoms (7.7\%) appears to be in the lower range as compared to international data. Age, marital status, and income appear to influence the variations in depressive symptoms. While the literature suggests more studies are needed to quantify the presence of depressive symptoms in non-western societies, the fact remains that depressive symptoms do exist. Hence, efforts are needed to reduce the burden of this psychologically debilitating condition.

\section{References}

1. Teljeur C, Smith SM, Paul G, Kelly A, Dowd TO (2013) Multimorbidity in a cohort of patients with type 2 diabetes. Eur J Gen Pract 19: 17-22. [crossref]

2. Graham EA, Deschênes SS, Khalil MN, Danna S, Filion KB, et al. (2020) Measures of depression and risk of type 2 diabetes: A systematic review and meta-analysis. J Affect Disord 265: 224-232. [crossref]

3. Kalan Farmanfarma KH, Ansari-Moghaddam A, Zareban I, Adineh HA (2020) Prevalence of type 2 diabetes in Middle-East: Systematic review\& meta-analysis. Prim Care Diabetes 14: 297-304.

4. International Diabetes Federation. IDF Diabetes Atlas. 9th ed. Brussels, Belgium: International Diabetes Federation; 2019

5. Saydah SH, Brancati FL, Golden SH, Fradkin J, Harris MI (2003) Depressive symptoms and the risk of type 2 diabetes mellitus in a US sample. Diabetes Metab Res Rev 19: 202-208. [crossref]

6. Wu CS, Hsu LY, Wang SH (2020) Association of depression and diabetes complications and mortality: a population-based cohort study. Epidemiol Psychiatr Sci 29: 96. [crossref]

7. Ali S, Stone MA, Peters JL, Davies MJ, Khunti K (2006) The prevalence of co-morbid depression in adults with Type 2 diabetes: a systematic review and meta-analysis. Diabet Med 23: 1165-1173. [crossref]

8. Egede LE, Ellis C (2010) Diabetes and depression: global perspectives. Diabetes Res Clin Pract 87: 302-312. [crossref]

9. Mendenhall E, Norris SA, Shidhaye R, Prabhakaran D (2014) Depression and type 2 diabetes in low- and middle-income countries: a systematic review. Diabetes Res Clin Pract 103: 276-285. [crossref]

10. Naja S, Al-Kubaisi N, Chehab M, Al-Dahshan A, Abuhashem N, et al. (2019) Psychometric properties of the Arabic version of EPDS and BDI-II as a screening tool for antenatal depression: evidence from Qatar. BMJ Open 9: 030365.

11. Donnelly TT, Al Suwaidi JM, Al-Qahtani A, Asaad N, Fung T, et al. (2016) Mood disturbance and depression in Arab women following hospitalisation from acute cardiac conditions: a cross-sectional study from Qatar. BMJ Open 6: 011873. [crossref]

12. Al-Sharbati M, Al-Adawi S, Petrini K, Amer ASB, Suleimani AA, et al. (2012) Two-phase survey to determine social anxiety and gender differences in Omani adolescents. Asia Pac Psychiatry 4: 131-139.

13. Al-Adawi S, Dorvlo AS, Burke DT, Moosa S, Al-Bahlani S (2002) A survey of anorexia nervosa using the Arabic version of the EAT-26 and "gold standard" interviews among Omani adolescents. Eat Weight Disord 7: 304-311. [crossref]

14. Al-Ghafri G, Al-Sinawi H, Al-Muniri A, Dorvlo ASS, Farsi YMA, et al. (2014) Prevalence of depressive symptoms as elicited by Patient Health Questionnaire (PHQ-9) among medical trainees in Oman. Asian J Psychiatr 8: 59-62. [crossref]

15. Jaju S, Al-Adawi S, Al-Kharusi H, Morsi M, Al-Riyami A (2009) Prevalence and ageof-onset distributions of DSM IV mental disorders and their severity among school going Omani adolescents and youths: WMH-CIDI findings. Child Adolesc Psychiatry Ment Health 3: 29. [crossref]

16. World Health Organization (1993) Composite International Diagnostic Interview. Geneva: WHO.

17. Al-Lawati JA, Panduranga P, Al-Shaikh HA, Morsi M, Mohsin N, et al. (2015) Epidemiology of Diabetes Mellitus in Oman: Results from two decades of research. Sultan Qaboos Univ Med J 15: 226-233. [crossref]

18. Al-Salmani A, Juma T, Al-Noobi A, Farsi YA, Jaafar N, et al. (2015) Characterization of depression among patients at urban primary healthcare centers in Oman. Int $J$ Psychiatry Med 49: 1-18. [crossref]

19. Alajmani DSA, Alkaabi AM, Alhosani MW, Folad AA, Abdouli FA, et al. (2019) Prevalence of Undiagnosed Depression in Patients With Type 2 Diabetes. Front Endocrinol (Lausanne) 10: 259. [crossref]

20. Mansori K, Shiravand N, Shadmani FK, Moradi Y, Allahmoradi M, et al. (2019) Association between depression with glycemic control and its complications in type 2 diabetes. Diabetes Metab Syndr 13: 1555-1560. [crossref]

21. Ahmadieh H, Itani H, Itani S, Sidani K, Kassem M, et al. (2018) Diabetes and depression in Lebanon and association with glycemic control: a cross-sectional study. Diabetes Metab Syndr Obes 11: 717-728. [crossref] 
22. Gemeay EM, Moawed SA, Mansour EA, Ebrahiem NE, Moussa IM, et al. (2015) The association between diabetes and depression. Saudi Med J 36: 1210-1215.

23. Roy M, Sengupta N, Sahana PK, Das C, Talukdar P, et al. (2018) Type 2 diabetes and influence of diabetes-specific distress on depression. Diabetes Res Clin Pract 143: 194-198. [crossref]

24. Koukouli S, Vlachonikolis IG, Philalithis A (2002) Socio-demographic factors and self-reported functional status: the significance of social support. BMC Health Serv Res 2: 20. [crossref]

25. Al-Sinawi H, Al-Alawi M, Al-Lawati R, Al-Harrasi A, Al-Shafaee M, et al. (2012) Emerging Burden of Frail Young and Elderly Persons in Oman: For whom the bell tolls? Sultan Qaboos Univ Med J 12: 169-176. [crossref]

26. Demakakos P, Pierce MB, Hardy R (2010) Depressive symptoms and risk of type 2 diabetes in a national sample of middle-aged and older adults: the English longitudinal study of aging. Diabetes Care 33: 792-797. [crossref]
27. Rotella F, Mannucci E (2013) Depression as a risk factor for diabetes: a meta-analysis of longitudinal studies. J Clin Psychiatry 74: 31-37. [crossref]

28. Batra S (2013) The psychosocial development of children: Implications for education and society-Erik Erikson in context. Contemporary Education Dialogue 10: 249-78.

29. Kaholokula JK, Haynes SN, Grandinetti A, Chang HK (2003) Biological, psychosocial, and sociodemographic variables associated with depressive symptoms in persons with type 2 diabetes. J Behav Med 26: 435-458. [crossref]

30. Dismuke CE, Egede LE (2010) Association between major depression, depressive symptoms and personal income in US adults with diabetes. Gen Hosp Psychiatry 32: 484-491. [crossref]

31. Storch EA, Roberti JW, Roth DA (2004) Factor structure, concurrent validity, and internal consistency of the Beck Depression Inventory-Second Edition in a sample of college students. Depress Anxiety 19: 187-189. [crossref] 